\title{
POLÍTICAS PÚBLICAS PARA AS COMUNIDADES QUILOMBOLAS NO BRASIL: UM ESTUDO À LUZ DA ANÁLISE LEXICAL NO PERÍODO DE 2000 A 2020
}

\author{
Witor Hugo Guedes Larrea \\ Graduado em Administração pela Universidade Estadual do Ceará - UECE. \\ E-mail: witor.larrea@aluno.uece.br \\ Francisca Diana Ferreira Viana \\ Doutorado em Economia pelo Centro de Desenvolvimento e Planejamento Regional (CEDEPLAR) da \\ Universidade Federal de Minas Gerais (UFMG). Atualmente é Professora do curso de Engenharia de \\ Produção da Universidade Federal de Ouro Preto - UFOP. \\ E-mail: dianaufu@gmail.com
}

Francisco Laércio Pereira Braga

Mestrado em Economia Rural pela Universidade Federal do Ceará - UECE. Atualmente é Professor da Universidade Estadual do Ceará - UECE

E-mail: laercio.braga@uece.br

\section{Resumo}

Este artigo tem por objetivo principal verificar os efeitos das políticas públicas nacionais no processo de construção e afirmação social das comunidades quilombolas remanescentes no Brasil por meio de trabalhos científicos nacionais publicados a partir dos anos 2000. A pesquisa foi realizada fazendo-se uso de uma análise bibliográfica de estudos publicados entre os anos 2000 e 2019 em plataformas digitais e analisados pelo software IRAMUTEQ. Através dessa análise verificou-se que a maior parte dos trabalhos publicados continha um ou mais temas que os aproximavam e, em sua maioria, foram publicados em revistas especializadas em políticas públicas. Ao final da análise, os resultados mostraram que apesar do grande número de políticas públicas desenvolvidas, nem todas são implementadas ou chegam às comunidades remanescentes de quilombos. Dessa maneira, as comunidades ficam dependentes dos interesses dos governos (federal, estadual ou municipal). Além disso, os trabalhos analisados, apesar de proximidade com a temática, pouco se conectam, o que os tornam distantes em suas abordagens.

Palavras-chave: Políticas Públicas. Quilombola. Comunidade.

\begin{abstract}
This article has as main objective to verify the effects of national public policies in the process of construction and social affirmation of the remaining Quilombola Communities in Brazil by means of national scientific works since the 2000s. The research was carried out using a bibliographic analysis of studies published from the 2000s on digital platforms and analyzed by the software IRAMUTEQ. Through this analysis, it was found that most of the published works contained one or more themes that brought them together and, for the most part, they were published in journals specialized in Public Policies. At the end of the analysis, the results showed that despite the large number of public policies developed, not all of them are implemented or reach the remaining quilombo communities. In this way, communities are dependent on the interests of governments (Federal, State or Municipal). In addition, the studies analyzed, despite their proximity to the theme, have little connection, which makes them distant in their approaches.
\end{abstract}

Keywords: Public Policies. Quilombola. Community. 


\section{INTRODUÇÃO}

O desenvolvimento de uma dada região ou país é permeado por complexas relações que estão intrinsecamente ligadas à cultura local, às instituições, à economia, ao meio ambiente e de como se dá a interação entre estes eixos. No caso brasileiro, um país com dimensões continentais, heterogêneo em cultura e assimétrico em termos de crescimento e desenvolvimento econômico, tanto entre quanto dentro das suas cinco regiões, os desafios rumo ao desenvolvimento se agigantam, sobretudo, em virtude das expressivas desigualdades socioeconômicas que caracterizam a sociedade brasileira.

A construção dessa sociedade no tripé monocultura, trabalho escravo e latifúndio, colaboraram, e ainda colaboram, de forma determinante, para a morosidade em se reduzir estas desigualdades ou ao menos se vislumbrar uma sociedade mais justa e igualitária, em que não apenas o crescimento econômico seja possível, mas os resultados desse crescimento possam se traduzir em desenvolvimento humano. Deste tripé, pode-se afirmar que a escravidão foi o pior pilar que deu sustentação à formação econômica do Brasil, com graves conseqüências que se estendem até os dias de hoje.

Esta afirmação pode ser constatada por meio do relatório da OXFAM Brasil, denominado "A Distância que nos une: um retrato das desigualdades brasileiras", publicado em setembro de 2017, quando aponta que:

Considerando todas as rendas, brancos ganhavam, em média, o dobro do que ganhavam negros, em 2015: $R \$ 1.589,00$ em comparação com $R \$$ 898,00 por mês. Em vinte anos, os rendimentos dos negros passaram de $45 \%$ do valor dos rendimentos dos brancos para apenas $57 \%$. Se mantido o ritmo de inclusão de negros observado nesse período, a equiparação da renda média com a dos brancos ocorrerá somente em 2089 (OXFAM, 2017, p.21).

As questões raciais no Brasil podem ser vistas e debatidas sob várias perspectivas que transitam no âmbito social, político e econômico. Ressalta-se que o fim da escravidão deve ser compreendido, também, sob o aspecto econômico e que apesar da abolição, nenhum direito político fora concedido aos negros da época (FERNANDES, 1989). Contudo, esse processo de privação política, social e econômica ocorreu de forma homogênea em todas as regiões do país, mesmo em áreas mais remotas, como foi o caso do Nordeste brasileiro.

A escravidão deu, portanto, suporte à vulnerabilidade socioeconômica ainda existente no Brasil atual. Dentro deste contexto, as comunidades quilombolas, 
assumem um papel de grande relevância no combate a essa vulnerabilidade, e na busca de um desenvolvimento pautado na valorização cultural, na diversificação produtiva, na sustentabilidade, na implantação de políticas públicas, sendo esta última a base para que os demais eixos de desenvolvimento aconteçam. Moura (1981) destaca que os quilombos surgem por volta do século XVI como forma de resistência dos negros que não aceitavam a escravidão e que fugiam das plantações ou de seus locais de trabalho forçado (engenhos e fazendas, por exemplo).

Assim, as primeiras comunidades Quilombolas constituíam-se como uma grande imagem de aldeias africanas, nas quais existiam divisões de tarefas, cultura de subsistência e a representação de um líder para que houvesse uma organização bem definida. Nota-se, dessa forma, que os quilombos já estavam constituídos bem antes da promulgação da Lei Áurea de 1888, como afirma Moura (1981, p.85), "em 1769 registrava-se a existência de um quilombo o qual recebia todos os negros fugidos", fato que reforçou a continuidade da existência dos quilombos agregando mais negros, que eram ex-escravos.

No Brasil, segundo mapeamento realizado pela Fundação Cultural Palmares (FCP), ligada até então ao extinto Ministério da Cultura (MinC), existem, segundo dados de maio de 2020, 3.432 comunidades remanescentes de quilombos, sendo o equivalente por região os seguintes números: 169 no Centro-Oeste, 2169 comunidades no Nordeste, 366 no Norte, 536 no Sudeste e 192 no Sul do país. Vale ressaltar que estes dados podem, muitas vezes, divergir dos que constam nas Coordenadorias Estaduais, pois o processo de verificação e confirmação é de total responsabilidade da Fundação Cultural Palmares como consta na Portaria FCP no 98, de 26/11/2007, dessa maneira pode haver divergência nas contagens de estados e municípios.

Diante deste panorama, surge a seguinte questão norteadora desta pesquisa: o que os trabalhos científicos brasileiros evidenciam sobre os efeitos das políticas públicas na construção e afirmação social das comunidades quilombolas remanescentes no Brasil? Sendo assim, este trabalho tem como objetivo verificar os efeitos das políticas públicas nacionais no processo de construção e afirmação social das comunidades quilombolas remanescentes no Brasil por meio de trabalhos científicos nacionais publicados a partir dos anos 2000. 
A justificativa e relevância do tema escolhido está pautada na importância em se estudar como as políticas públicas implementadas nas comunidades quilombolas remanescentes no Brasil podem trazer resultados significativos a essas comunidades. Além disso, os resultados desta pesquisa contribuirão para o debate sobre a incipiência de estudos da temática, já que muitas das comunidades se encontram em regiões distantes dos grandes centros urbanos e metrópoles do País. Dessa maneira, trata-se, primeiramente, de um trabalho com aspecto de ineditismo na literatura acadêmica por se utilizar dos resultados fornecidos a partir do software IRAMUTEQ que será aplicado aos artigos científicos nacionais desta temática; e segundo, a relevância deste tipo de análise fornece a possibilidade de identificação de gaps teóricos que podem auxiliar possíveis trabalhos futuros, assim como as formulações de políticas públicas.

\section{REVISÃO DA LITERATURA}

\subsection{Das políticas públicas às comunidades remanescentes de quilombolas}

Dentre as diferentes definições sobre o que é e como podem ser adotadas, as políticas públicas evidenciam que nem toda ação tomada vai, diretamente, beneficiar a todos os indivíduos. É nesse sentido que algumas ações governamentais tentam corrigir questões sociais, econômicas ou políticas, ou apenas tentam, através de programas sociais, educacionais, ou de incentivos, cumprir o que é estabelecido pela Constituição Federal (1988) em suas cláusulas pétreas.

No geral, as políticas públicas são de interesse de bem comum, que tem como objetivo atingir a toda população de maneira eficiente, a fim de corrigir assimetrias, ou de criar mecanismos para a melhoria de vida e desenvolvimento social e econômico, o que nem sempre é visto como um bem comum (SOUZA, 2006).

A Constituição Federal de 1988 assegurou, através de uma política pública de Estado, o direito à terra às comunidades quilombolas através de sua titulação, o que não necessariamente pode ser concluído como o cumprimento e a aquirência das terras de maneira geral, pois somente cerca de 20 anos depois surgiram 
políticas públicas que foram capazes de avançar nesse assunto em específico. Esse marco deu-se com o Decreto Federal número 4.887 de 2003, por meio dos "processos de regulamentação fundiária realizada pelo Instituto Nacional de Colonização e Reforma Agrária - INCRA", (URQUIZA; SANTOS, 2017, p.237), onde se constituiu, de maneira mais eficaz, que o reconhecimento das comunidades remanescentes de quilombos ia bem além apenas do reconhecimento cultural, mas do direito inviolável à terra que pertencia a seus antepassados. Os desdobramentos que ocorrem a partir desse reconhecimento territorial viabilizaram as lutas das comunidades, não apenas pelo direito à terra, mas na busca por outras políticas públicas que visassem ao atendimento diferenciado à saúde, educação voltada para comunidades quilombolas e, também, às atividades econômicas que, em geral, são prioritariamente as de agricultura familiar no campo.

Mesmo com a criação da Fundação Cultural Palmares (FCP), as políticas públicas destinadas às comunidades do campo e indenitárias, quilombolas e indígenas, só começaram, de fato, a serem implementadas a partir dos anos 2000 (PERES; MOURA, 2018). Embora em 1996 tenha havido o lançamento do Programa Nacional de Agricultura Familiar (PRONAF), foi somente em 2004, que a cultura familiar (que corresponde a $40 \%$ de toda produção agrícola do país) aumentou seu protagonismo no cenário nacional (LUCENA; LIMA; PEREIRA, 2016).

Ainda segundo Lucena, Lima e Pereira (2016), mesmo com o PRONAF, as comunidades quilombolas não conseguiam tornar sua estrutura produtiva mais competitiva por não incorporar os avanços tecnológicos e industriais agrícolas existentes, resultando em uma grande exclusão e endividamento no processo de produção da agricultura familiar, tendo em vista seus métodos de produção e ferramentas considerados ultrapassados (utilização de enxada, foice e afins). $\mathrm{Na}$ gestão do governo Lula (2003-2010) foi consolidado o Programa Brasil Quilombola (PBQ), possibilitando que grupos quilombolas pudessem ter acesso às adequações mínimas de infraestrutura, educação, programas sociais (como bolsa família), inclusão produtiva, acesso a terra, entre outros, o que deu garantia de desenvolvimento e sobrevivência a essas comunidades.

A partir dos desdobramentos do reconhecimento da demarcação de terra de comunidades quilombolas e indígenas, as comunidades passaram a cobrar políticas de ensino voltadas à educação quilombola, um abismo que os governos não 
suprem, mesmo com as políticas públicas adotadas no âmbito federal, já que o ensino de base é de responsabilidade dos estados e municípios (SANTOS et al., 2019).

Um dos principais projetos criados foi o Projeto de Lei 10.639/03, que estabeleceu o ensino obrigatório de História da África e História Afro-brasileira na matriz curricular das escolas públicas e privadas, no ensino fundamental e médio e que instituiu o dia 20 de novembro como "Dia da consciência Negra" no calendário oficial. Em 2008 essa lei foi substituída pela Lei 11.645/08, que incluiu, também, o ensino sobre História e Cultura Indígena. Deve-se ressaltar que ambas as leis são complementares à Lei 9.394/96 que implementou as diretrizes de base da educação nacional (PÊSSOA, 2010). Dentro desse entendimento de políticas públicas voltadas ao ensino da História negra no Brasil, a representatividade e promoção da cultura quilombola são tidas como sujeitos da História, mas há ainda outros fatores a serem considerados, ou seja, era preciso entender a realidade das comunidades remanescentes de quilombos. No entanto, somente em 2012, por meio do Art. 1 da Resolução 8/2012 do Conselho Nacional de Educação (CNE), foi implementado o Ensino de Quilombo das Escolas (EQE), que gerou a possibilidade de criação de Escolas de Educação Escolar Quilombola (EEEQ).

Mesmo com todos os aparatos para que isso ocorra, percebe-se que ainda há uma grande deficiência em atender as comunidades quilombolas, seja pela questão geográfica (distância e população) ou pela falta de interesse dos governos locais em dar o suporte necessário para o acesso à educação adequada a essas comunidades. Além disso, o governo federal é responsável apenas pelo repasse das verbas, já que a educação de base não é de sua responsabilidade geral direta, o que torna ainda mais difícil a implementação das políticas públicas voltadas para a educação quilombola (SANTOS et al., 2019).

Dentre todos esses contextos, vale lembrar que, em 2013, no governo de Dilma Rousseff (2011-2016), foi lançado um "Guia para políticas públicas para comunidades quilombolas", onde são explicados os projetos em curso do governo Federal do "Programa Brasil Quilombola" (PBQ). Tanto no Guia quanto nos projetos constam muitas outras conquistas das comunidades remanescentes de quilombos, dentre as quais aquelas que remetem à infraestrutura das comunidades, como "Luz para todos", "Água para todos", instalação de cisternas, regulação fundiária, 
"assistência técnica e inclusão rural", além de programas de educação como, por exemplo, o TELECENTRO (inclusão digital), Programa Nacional de Alimentação Escolar (PNAE) e programa de acesso técnico a emprego.

\section{PROCESSOS METODOLÓGICOS}

\subsection{Origem dos dados e período temporal da pesquisa}

O horizonte temporal da pesquisa deu-se a partir dos anos 2000, levando em conta a quantidade de obras publicadas e a importância das políticas públicas para as comunidades remanescentes de quilombos nesse período de tempo, tendo em vista que a maior parte das políticas públicas destinadas às comunidades remanescentes de quilombos foi aplicada nesse período. Dessa forma, inicialmente foram encontrados 40 artigos que trataram sobre diversas áreas, conforme explicitado no Quadro 1.

Quadro 1 - Quantidade de artigos e trabalhos encontrados por área

\begin{tabular}{|c|c|}
\hline TEMA & QUANTIDADE \\
\hline EDUCAC̃̃OO & $6^{*}$ \\
\hline POLÍTICAS PỦBLICAS & $21^{*}$ \\
\hline AGRICULTURA FAMILIAR & $7^{*}$ \\
\hline DEMARCAÇ̃̃O TERRITORIAL & $6^{*}$ \\
\hline TOTAL & 40 \\
\hline
\end{tabular}

Fonte: Elaborado pelos autores com base nas escolhas bibliográficas (2020).

Em seguida, deu-se início aos filtros para seleção dos artigos utilizando-se o procedimento metodológico escolhido para este trabalho. Então, tiveram-se as seguintes orientações: a) observar e selecionar artigos nacionais (escrito em português); b) aqueles que apresentavam dentre suas palavras-chave os seguintes vocábulos: "quilombos", ou "quilombolas", ou "políticas públicas", ou todos eles; c), além disso, optou-se pelo filtro temporal, ou seja, trabalhos com essas temáticas a partir dos anos 2000 até 2019, e que pesquisaram as políticas públicas na mesma época referente às comunidades quilombolas por todo o país (Figura 1). 


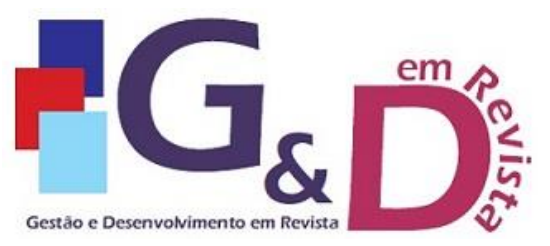

Gestão e Desenvolvimento em Revista V. 7, N. 1, jan-jun/2021, p. 100-121.

ISSN online: $2446-8738$

Artigo recebido em: 12/05/2021

Artigo aprovado em: 12/07/2021

Figura 1: Procedimento metodológico da pesquisa

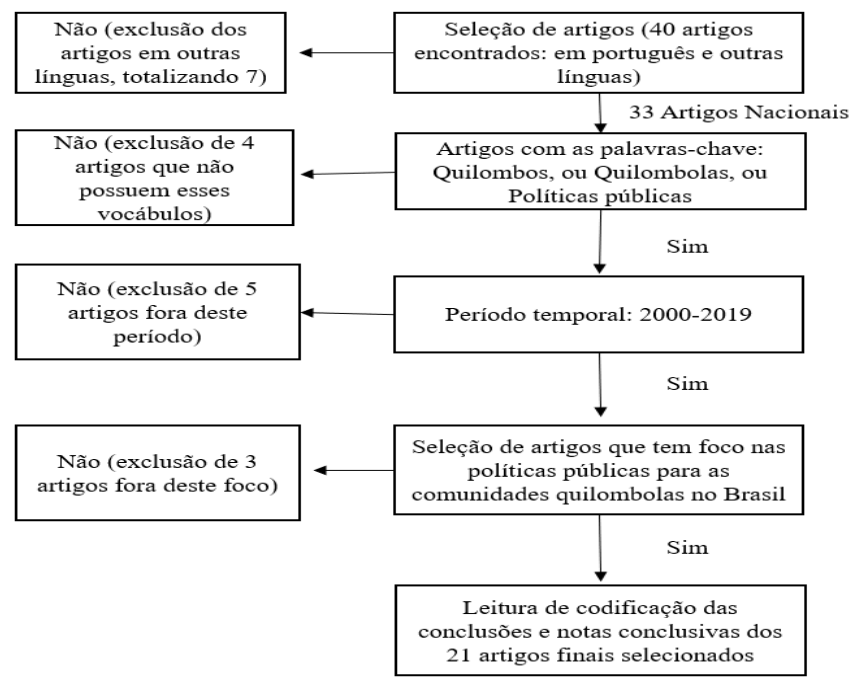

Fonte: Elaboração própria, 2021.

Assim, ao todo, foram escolhidos 21 artigos nacionais para terem suas conclusões ou notas conclusivas codificadas e analisadas pelo software IRAMUTEQ. Dentre os temas, a maior parte foi de publicações em revistas anuais especializadas em políticas públicas, simpósios, artigos científicos universitários, cadernos de publicações científicas recorrentes, colóquios e revistas especializadas em temáticas quilombolas ou de comunidades indenitárias, como indígenas e remanescentes de quilombos (Quadro 2).

Quadro 2 - Trabalhos científicos selecionados para análise textual

\begin{tabular}{|c|c|c|c|}
\hline ARTIGOS & AUTOR(ES) & TÍTULO & PERIÓDICO/ANO \\
\hline Artigo_1 & $\begin{array}{l}\text { LUCENA; LIMA; } \\
\text { PEREIRA }\end{array}$ & $\begin{array}{l}\text { A Agricultura Familiar na Comunidade Quilombola Pêga, } \\
\text { em Portoalegre - RN }\end{array}$ & GEOtemas, 2016 \\
\hline Artigo_2 & SOUZA & Introdução Políticas Públicas: uma revisão da literatura & Sociologias, 2006 \\
\hline Artigo_3 & URQUIZA; SANTOS & $\begin{array}{l}\text { Regularização fundiária de comunidades quilombolas em } \\
\text { Mato Grosso do Sul/Brasil }\end{array}$ & $\begin{array}{l}\text { Revista Brasileira de Políticas } \\
\text { Públicas, } 2017\end{array}$ \\
\hline Artigo_4 & $\begin{array}{l}\text { PERES; MOURA; } \\
\text { COSTA }\end{array}$ & $\begin{array}{l}\text { Investimentos para a Educação Quilombola no Ceará: } \\
\text { Entre a Legislação, Políticas Educacionais e Desafios da } \\
\text { Realidade }\end{array}$ & $\begin{array}{l}\text { Anais do III Seminário Anual da } \\
\text { Rede Mapa, } 2018\end{array}$ \\
\hline Artigo_5 & SANTOS et al., 2019 & $\begin{array}{l}\text { Oferta de Escolas de Educação Escolar Quilombola no } \\
\text { Nordeste Brasileiro }\end{array}$ & Educação \& Realidade, 2019 \\
\hline Artigo_6 & PÊSSOA & ( $\mathrm{Re})$ Construindo a História Afrobrasileira e Indígena & $\begin{array}{l}\text { IV Colóquio de História. } \\
\text { UNICAMP, nov. } 2010 .\end{array}$ \\
\hline Artigo_7 & CHAVES; SILVA & $\begin{array}{l}\text { Comunidades Negras no Ceará: da Invisibilidade à } \\
\text { Formação dos Quilombos Contemporâneos }\end{array}$ & Novos Cadernos NAEA, 2017 \\
\hline Artigo_8 & ARAÚJO et al. & $\begin{array}{l}\text { Análise Socioeconômica de agricultores da comunidade } \\
\text { quilombola do Abacatal, Ananindeua, estado do Pará, } \\
\text { Brasil }\end{array}$ & Biota Amazônia, 2017 \\
\hline Artigo_9 & $\begin{array}{l}\text { CARVALHO; } \\
\text { LIMA }\end{array}$ & $\begin{array}{l}\text { Comunidades Quilombolas Territorialidade e a Legislação } \\
\text { no Brasil: uma análise histórica }\end{array}$ & Revista de Ciências Sociais, 2013 \\
\hline Artigo_10 & $\begin{array}{l}\text { VELLOSO; } \\
\text { CASTANHEIRA }\end{array}$ & $\begin{array}{l}\text { Inclusão Digital e Práticas de Leitura em um Telecentro } \\
\text { de uma Comunidade Quilombola }\end{array}$ & Revista Diálogo Educacional, 2019 \\
\hline Artigo_11 & SANTOS & $\begin{array}{l}\text { Os Quilombos e sua Inserção nas Políticas Públicas: } \\
\text { subsídios à discussão da política de ATER quilombola }\end{array}$ & Revista de Políticas Públicas, 2017 \\
\hline Artigo_12 & RODRIGUES & Políticas Públicas de Desenvolvimento Territorial para a & Cadernos Ceru, 2015 \\
\hline
\end{tabular}




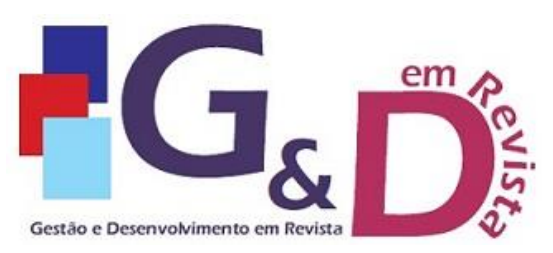

Gestão e Desenvolvimento em Revista V. 7, N. 1, jan-jun/2021, p. 100-121.

ISSN online: $2446-8738$

Artigo recebido em: 12/05/2021

Artigo aprovado em: 12/07/2021

\begin{tabular}{|c|l|l|l|}
\hline & & População Quilombola: Algumas Considerações; & \\
\hline Artigo_13 & $\begin{array}{l}\text { DUNCK DALOSTO; } \\
\text { DUNCK DALOSTO }\end{array}$ & $\begin{array}{l}\text { Políticas Públicas e os Quilombos no Brasil: da Colônia } \\
\text { ao Governo Michel Temer; }\end{array}$ & Revista de Políticas Públicas, 2018 \\
\hline Artigo_14 & SILVA & $\begin{array}{l}\text { Políticas Públicas para Comunidades Quilombolas: uma } \\
\text { luta em construção }\end{array}$ & Revista de Ciências Sociais, 2018 \\
\hline Artigo_15 & SOARES & $\begin{array}{l}\text { Conflitos Socioambientais e a Ameaça a ao Processo de } \\
\text { Demarcação de Terras Quilombolas no Brasil; }\end{array}$ & Revista de Políticas Públicas; 2018 \\
\hline Artigo_16 & $\begin{array}{l}\text { BRANDÃO; } \\
\text { JORGE }\end{array}$ & $\begin{array}{l}\text { Congresso Conservador e Ameaças aos Direitos } \\
\text { Quilombolas }\end{array}$ & Revista de Políticas Públicas; 2018 \\
\hline Artigo_17 & COSTA; SCARCELLI & $\begin{array}{l}\text { Psicologia, Política Pública para a População Quilombola } \\
\text { e Racismo }\end{array}$ & Psicologia - USP, 2016 \\
\hline Artigo_18 & $\begin{array}{l}\text { SILVA; } \\
\text { LIMA }\end{array}$ & $\begin{array}{l}\text { Quilombos no Ceará: Desafio ao Acesso de Direitos aos } \\
\text { Territórios }\end{array}$ & $\begin{array}{l}\text { IV Congresso Nacional } \\
\text { Africanidades e Brasilidades, 2018 }\end{array}$ \\
\hline Artigo_19 & $\begin{array}{l}\text { SILVA; } \\
\text { LIMA }\end{array}$ & $\begin{array}{l}\text { Territórios Quilombolas no Ceará: Educação, Processo } \\
\text { Histórico e Identidades }\end{array}$ & $\begin{array}{l}\text { Brazilian Journal of Development, } \\
\text { 2019 }\end{array}$ \\
\hline Artigo_20 & $\begin{array}{l}\text { SCHMITT; TURATTI; } \\
\text { CARVALHO }\end{array}$ & $\begin{array}{l}\text { A Atualização do Conceito de Quilombo: Identidade e } \\
\text { Territórios nas Definições Teóricas }\end{array}$ & Ambiente \& Sociedade, 2002 \\
\hline Artigo_21 & BRASIL & $\begin{array}{l}\text { Programa Brasil Quilombola } \\
\text { Guia de Políticas Públicas para } \\
\text { Comunidades Quilombolas, 2013 }\end{array}$ \\
\hline
\end{tabular}

Fonte: Elaborado pelo autor com base nas escolhas bibliográficas (2020).

\subsection{Instrumento de análise}

A análise da pesquisa ocorreu através da utilização do software livre para análises, principalmente sociais, mas também apropriado para análises qualitativas e quantitativas conjuntamente. O IRAMUTEQ, Interface de $R$ pour les Analyses Multidimensionnelles de Textes et de Questionnaires (IRAMUTEQ), foi criado em 2009 na França por Pierre Ratinaud, mas só utilizado no Brasil a partir do ano de 2013 (SOUZA, 2017). O software IRAMUTEQ, foi escolhido pois:

"O IRAMUTEQ possibilita os seguintes tipos de análises: estatísticas textuais clássicas; pesquisa de especificidades de grupos; classificação hierárquica descendente; análises de similitude e nuvem de palavras. Pelo seu rigor estatístico, pelas diferentes possibilidades de análise, interface simples e compreensível, e, sobretudo, por seu acesso gratuito, o IRAMUTEQ pode trazer muitas contribuições aos estudos em ciências humanas e sociais, que têm o conteúdo simbólico proveniente dos materiais textuais como uma fonte importante de dados de pesquisa" (CAMARGO; JUSTO, 2009, p. 513).

\section{RESULTADOS E DISCUSSÃO}

Após realizar a interseção dos vinte e um artigos (21) utilizados na pesquisa, foram identificadas, através do software IRAMUTEQ, a separação de corpus de 21 unidades de textos iniciais (UCE's), com 231 segmentos de textos (ST), 2.270 formas distintas de vocábulos e 8.207 ocorrências de palavras nos textos. Dito isso, além desses, foram detectadas 1.552 palavras que são mencionadas apenas uma 
única vez no texto, as chamadas hápax, correspondendo a um total de $18,91 \%$ das 8.207 ocorrências de palavras, ou seja, $81 \%$ das palavras apareceram mais de duas vezes ao longo de todo o corpus textual formado pelos vinte e um artigos selecionados.

A Nuvem de Palavras é uma forma, por exemplo, de se mostrar o conjunto de palavras principais agrupadas, organizadas e estruturadas em forma de nuvem, de acordo com seu maior grau de repetição no corpus textual (SALVIATI, 2017). A nuvem é formada pelo software IRAMUTEQ, o que torna mais simples de se analisar a lexia das palavras e ajuda a compreender, de maneira rápida, a importância de cada palavra-chave. Assim, nota-se que as palavras mais importantes e repetidas encontram-se na parte central da nuvem em tamanhos maiores, face aquelas menos repetidas em tamanhos menores e mais afastadas da região central. Como era o esperado, as palavras quilombola, comunidade, político, público e direito aparecem em maior destaque (Figura 2).

Figura 2 - Nuvem de palavras

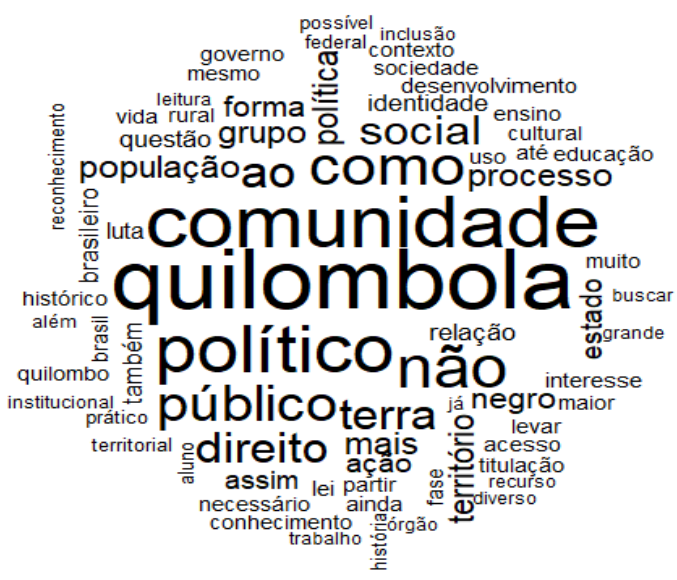

Fonte: Elaborada pelos autores a partir do software IRAMUTEQ (2021).

Para a análise de aproximação e distanciamento de fatores textuais foi elaborado um dendograma a partir do corpus textual composto por cinco clusters (Figura 3). Dessa maneira, é possível explicar a criação de cada cluster a priori e, posteriormente, entender os pontos que convergem ou se distanciam nos textos pesquisados. A avaliação da Classificação Hierárquica Descendente (CHD) ocorre de duas formas: i) grupos identificados como solitários, ou seja, contextos com possibilidade única ou menor possibilidade de conexão entre os demais grupos; ii) 
classe de grupos que possuem elevada porcentagem de conexão entre eles e com maior contemplação do corpus analisado. Salientar que para uma leitura correta deste dendograma, deve-se analisar da esquerda para a direita.

No processo de construção do dendograma, os cinco clusters foram divididos em dois subcorpus (R1 e R2). No subcorpus R1, a classe 5 (lilás) representa $21,1 \%$ do corpus textual, a classe 1 (vermelha) representa $18,3 \%$ do corpus e a classe 2 (cinza) representa 18,3\%, juntos significam $57,7 \%$ do total do corpus textual. Já as classes pertencentes ao subcorpus R2, apresentam os seguintes resultados: classe 3 (verde) refere-se a 22,3\% do corpus textual e a classe 4 (azul) 20\% do corpus. Importante lembrar que a proximidade das classes é compatível com a conexão textual que possuem, ou seja, quanto mais próximas, maior será a conectividade entre os assuntos abordados nos textos analisados. Isto significa que os artigos que compõem, por exemplo, as classes 5, 1 e 2 conversam, de alguma forma, mais entre si do que as demais classes identificadas.

Figura 3 - Classificação Hierárquica Descendente (CHD)

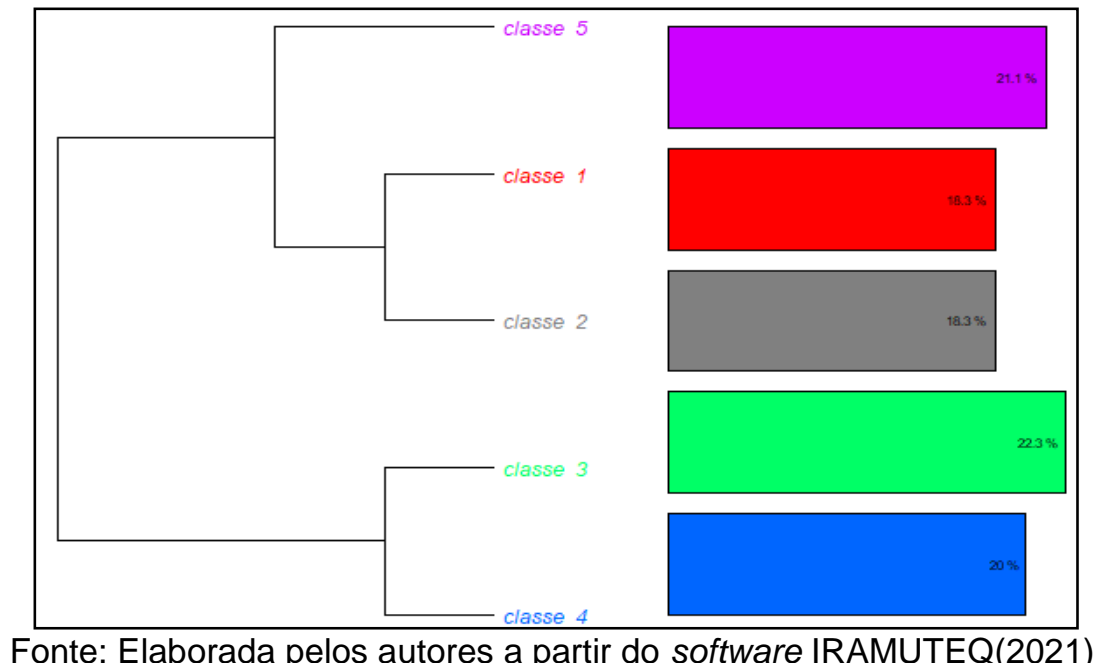

Dentro do CHD, podem-se observar os ramos que representam as conexões ocorridas no corpus textual que foram desenvolvidas pelo software e consegue-se analisar, ainda, a ordem das palavras e o tamanho no filograma. Esse mecanismo permite destacar o grau de importância e a influência das palavras-chave dentro da classe, o que adicionam mais detalhes a análise dos resultados adquiridos. Assim, notam-se, com a Figura 4, as principais palavras de cada classe do CHD, ou seja, na classe 4, por exemplo, os artigos trataram de assuntos que giravam em torno de territorial, associações, desenvolvimento, programa e governo. Na classe 3, têm-se 


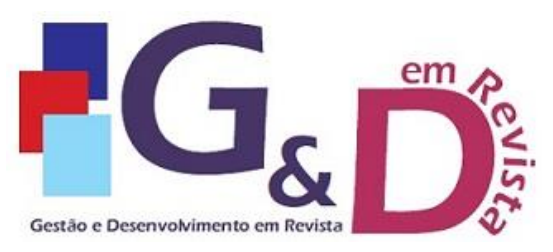

Gestão e Desenvolvimento em Revista V. 7, N. 1, jan-jun/2021, p. 100-121.

ISSN online: $2446-8738$

Artigo recebido em: 12/05/2021

Artigo aprovado em: 12/07/2021

os assuntos relacionados a público, acesso, informação, racismos etc., e assim sucessivamente.

Figura 4 - Dendograma da CHD do corpus textual

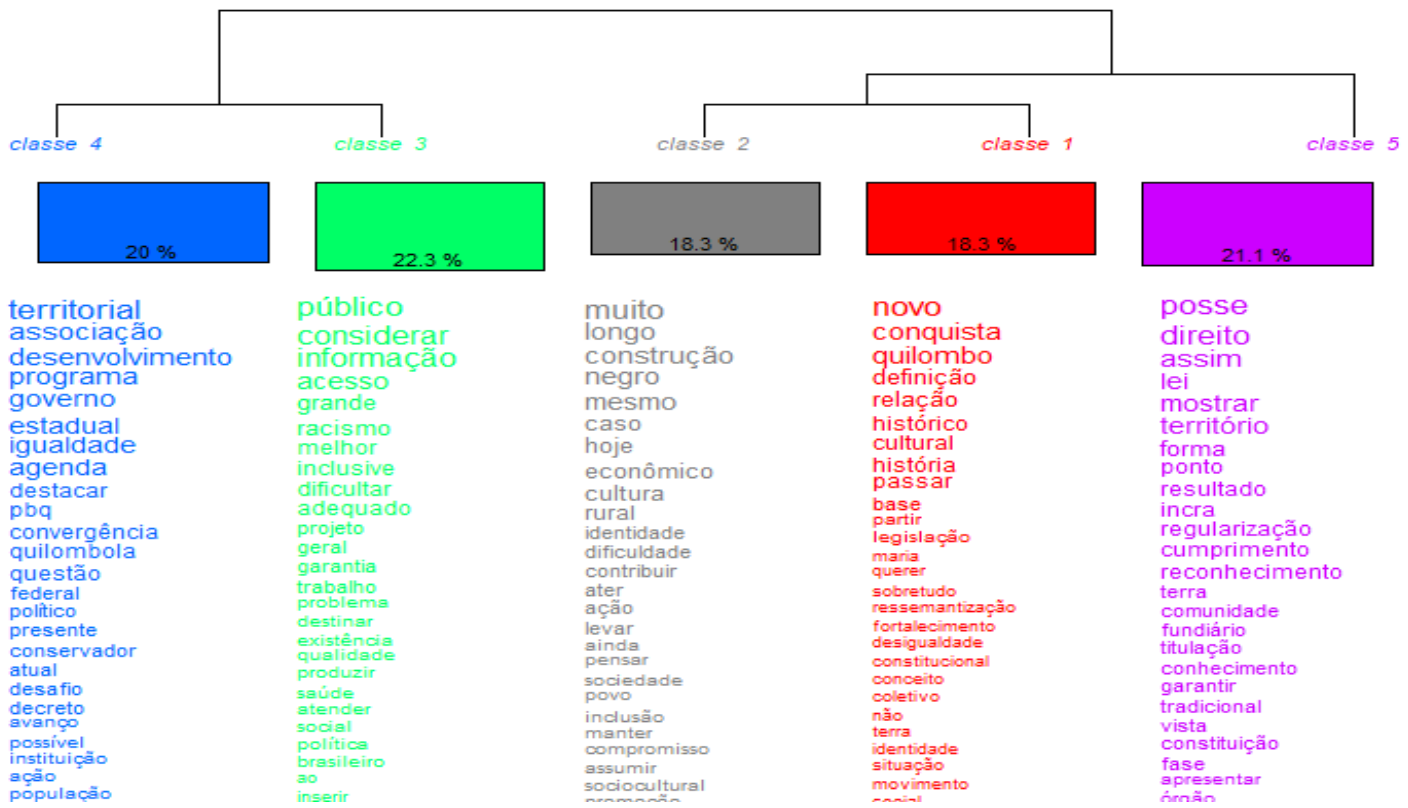

Fonte: Elaborado pelos autores a partir do software IRAMUTEQ (2021).

A partir da análise e construção do CHD, pode-se perceber a formação das classes em seu corpus textual, sobretudo no quadro 3, onde observam-se os trabalhos e principais grupos de autores e seus temas aproximados, tendo em vista os diversos assuntos abordados na construção de políticas públicas voltadas às comunidades quilombolas.

Desta forma, nota-se a presença, na classe 1, de trabalhos que retratam as análises e construções sociais, histórias e identitárias. Na classe 2, constata-se a luta pela territorialidade, agricultura familiar e cumprimento dos direitos constitucionais. A classe 3, por sua vez, agrega estudos sobre a abordagem do tema econômico, conflitos sociais e o poder do Estado, no ponto de recursos a serem investidos em ações para essas comunidades. As ações governamentais e seus impactos, os projetos não constitucionais ou a falta dos mesmos, aparecem na classe 4, enquanto na classe 5 são apresentados os novos modelos voltados ao desenvolvimento, inclusão e avanço nas ações de políticas públicas. 
Quadro 3 - Artigos selecionados que formam o Corpus de textos segundo suas classes

\begin{tabular}{|c|c|c|c|c|}
\hline Classe $1(18,3 \%)$ & Classe $2(18,3 \%)$ & Classe $3(22,3 \%)$ & Classe $4(20 \%)$ & Classe $5(21.1 \%)$ \\
\hline PÊSSOA; 2010 & $\begin{array}{l}\text { LUCENA; LIMA; } \\
\text { PEREIRA, } 2016\end{array}$ & SOUZA, 2006 & RODRIGUES, 2015 & URQUIZA; SANTOS, 2017 \\
\hline $\begin{array}{l}\text { CARVALHO; LIMA, } \\
2013\end{array}$ & SANTOS, 2017 & SANTOS et al., 2019 & \begin{tabular}{|c|} 
DUNCK DALOSTO; \\
DUNCK DALOSTO, 2018 \\
\end{tabular} & CHAVES; SILVA, 2017 \\
\hline BRANDÃO; JORGE, 2018 & SILVA, 2018 & $\begin{array}{l}\text { PERES; MOURA; } \\
\text { COSTA, } 2018 \\
\end{array}$ & BRASIL, 2013 & $\begin{array}{c}\text { VELOSO; CASTANHEIRO, } \\
2019 \\
\end{array}$ \\
\hline $\begin{array}{c}\text { COSTA; SCARCELLI, } \\
2016\end{array}$ & $\begin{array}{c}\text { SILVA; LIMA, } \\
2018\end{array}$ & ARAÚJO et al, 2017 & & \\
\hline SILVA; LIMA, 2019 & & SOARES, 2018 & & \\
\hline $\begin{array}{l}\text { SCHMITT; TURATTI; } \\
\text { CARVALHO, } 2002\end{array}$ & & & & \\
\hline
\end{tabular}

Fonte: Elaborada pelos autores a partir do software IRAMUTEQ (2021).

Para a construção do dendograma, foram utilizadas as palavras que eram consideradas as mais relevantes por sua frequência maior ou igual à frequência média registrada, $x \mathbf{2}$ maior ou igual a 20 e $p$ de significância $\leq 0,0001$. Neste dendograma, observam-se as diferenças dos vocábulos e os que conseguiram maior frequência média entre si. Na Tabela 1, notam-se apenas as palavras com maior significância nas classes e suas respectivas associações com a classe ( $\left.\boldsymbol{X}^{2}\right)$. Assim, a composição das palavras demonstra entre si o grau de relevância que possuem no grupo de artigos os quais compõem, sempre observando sua frequência média, ou seja, quanto mais ao topo, maior a frequência média da presença no corpus textual.

Tabela 1 - Vocábulos estatisticamente significativos em cada cluster do corpus textual

\begin{tabular}{|c|c|c|c|}
\hline Palavra & Porcentagem (\%) & $x^{2}$ & $\mathbf{p}$ \\
\hline \multicolumn{4}{|c|}{ CLASSE $1(18,29 \%)$} \\
\hline Novo & 100,00 & 32,58 & $<0,0001$ \\
\hline Conquista & 100,00 & 27,76 & $<0,0001$ \\
\hline Quilombo & 75,00 & 27,73 & $<0,0001$ \\
\hline Definição & 83,33 & 17,59 & $<0,0001$ \\
\hline Relação & 56,25 & 16,99 & $<0,0001$ \\
\hline Histórico & 63,64 & 16,16 & $<0,0001$ \\
\hline Palavra & Porcentagem (\%) & $\chi^{2}$ & p \\
\hline \multicolumn{4}{|c|}{ CLASSE $2(18,29 \%)$} \\
\hline Muito & 72,73 & 23,28 & $<0,0001$ \\
\hline Longo & 100,00 & 18,29 & $<0,0001$ \\
\hline Construção & 83,33 & 17,59 & $<0,0001$ \\
\hline Negro & 52,63 & 16,83 & $<0,0001$ \\
\hline \multicolumn{4}{|c|}{ CLASSE $3(22,29 \%)$} \\
\hline Público & 51,28 & 24,36 & $<0,0001$ \\
\hline Considerar & 100,00 & 21,67 & $<0,0001$ \\
\hline Informação & 87,5 & 20,59 & $<0,0001$ \\
\hline Acesso & 72,73 & 17,24 & $<0,0001$ \\
\hline \multicolumn{4}{|c|}{ CLASSE $4(20 \%)$} \\
\hline Territorial & 100,00 & 24,85 & $<0,0001$ \\
\hline
\end{tabular}




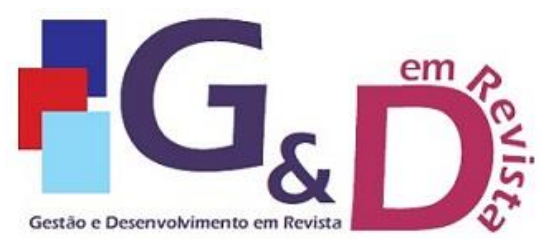

Gestão e Desenvolvimento em Revista V. 7, N. 1, jan-jun/2021, p. 100-121.

ISSN online: $2446-8738$

Artigo recebido em: 12/05/2021

Artigo aprovado em: 12/07/2021

\begin{tabular}{l|c|c|c}
\hline \multicolumn{1}{l|}{ Associação } & 100,00 & 20,59 & $<0,0001$ \\
\hline Desenvolvimento & 72,73 & 20,4 & $<0,0001$ \\
\hline Programa & 85,71 & 19,68 & $<0,0001$ \\
\hline Governo & 70,00 & 16,57 & $<0,0001$ \\
\hline Estadual & 100,00 & 16,37 & $<0,0001$ \\
\hline Igualdade & 100,00 & 16,37 & $<0,0001$ \\
\hline Agenda & 100,00 & 16,37 & $<0,0001$ \\
\hline Posse & \multicolumn{2}{|c|}{ CLASSE 5(21,14\%) } & $<0,0001$ \\
\hline Direito & 100 & 23,17 & $<0,0001$ \\
\hline Assim & 50 & 19,56 & $<0,0001$ \\
\hline Lei & 64,29 & 16,99 & $<0,0001$ \\
\hline Mostrar & 66,67 & 16,01 & $<0,0001$ \\
\hline
\end{tabular}

Fonte: Elaborada pelos autores a partir do software IRAMUTEQ (2021).

Ao todo, após ser aplicada uma análise fatorial explicativa, foram extraídos 4 fatores do total dos 21 artigos analisados, onde pode-se observar que os fatores $1 \mathrm{e}$ 2 correspondem, juntos, a mais de $52 \%$ de capacidade de explicar o total da variância de vocábulos no corpus. Já, individualmente, têm-se os seguintes valores dos resultados obtidos: i) o fator 1 representa $31,3 \%$ da variância total, com atenuado grau de relevância relacionada à temática abordada; ii) o fator 2 representa $25,8 \%$; iii) o fator 3 , da mesma forma, representa $22,6 \%$; e, iv) o fator 4 , com 20,3\% da variância (Tabela 2). Dessa maneira, para análises posteriores, consideraram-se apenas os dois primeiros fatores obtidos para a elaboração do mapa fatorial, determinado pelos vocábulos mais frequentes e relevantes.

Tabela 2 - Autovalores e percentagem da variância total explicada pelos fatores

\begin{tabular}{lccc}
\hline Fator & Autovalores & Porcentagem & Porcentagem acumulada \\
\hline Fator 1 & 0,33604 & 31,3105 & 31,3105 \\
\hline Fator 2 & 0,27675 & 25,7863 & 57,0968 \\
\hline Fator 3 & 0,24292 & 22,6338 & 79,7307 \\
\hline Fator 4 & 0,21754 & 20,2693 & 100,00 \\
\hline
\end{tabular}

Fonte: Elaborada pelos autores a partir do software IRAMUTEQ (2021).

A distribuição dos elementos lexicais que ocorrem dentro da Analise Fatorial de Correspondência (AFC) (Figura 5), mostra, também, seus respectivos campos léxico-semânticos. O cruzamento dos vocabulários considerados frequentes e as classes que os mesmos compõem está representado no plano cartesiano, onde a linha horizontal traduz as mais fortes palavras ou expressões de destaque no conjunto de artigos, enquanto a linha vertical refere-se ao fator 2. Logo, após a construção da AFC, constata-se o quão próximos estão os assuntos abordados 
entre os artigos. No fator 1 encontram-se artigos que trataram de temas sobre, por exemplo, conquista, quilombo, relação, cultural, definição, etc. onde estas palavras apresentam correlações negativas entre si (quadrante direito inferior). No fator 2 , deparou-se com conjunto de artigos que versaram, por exemplo, sobre quilombola, comunidade, território, conhecimento.

Ao analisar a classe 1 (vermelha) e a classe 2 (cinza), verifica-se que muitos dos artigos dessas classes se mesclam constantemente, pois possuem argumentos próximos. Já a classe 3 (verde) possui maior distanciamento da classe 5 (lilás), com pequenas mesclas com as classes 1 e 2, mas, no geral, estão mais distantes em seu quadrante. Quando se observa a classe 4 (azul), é possível ver que é a classe que menos se integra com as demais, mesmo se aproximando das classes 3 e 5 . Por fim, a classe 5 (lilás) tende a interagir menos com as demais classes, porém tem proximidade com a classe 1 .

Essa análise da AFC, através das aproximações e distanciamentos lexicais dos artigos, mostra que apesar desse artigo ser voltado para o estudo das políticas públicas nas comunidades Quilombolas, os mesmos não conseguem direcionar ou conversar entre si e com as demandas existentes, abrindo espaço para futuros trabalhos que abordem os temas. 


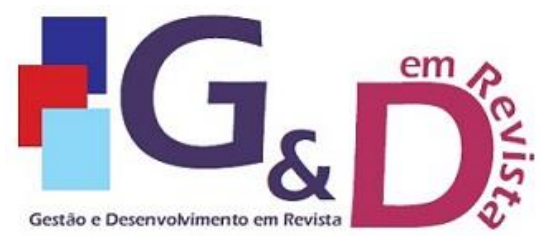

Gestão e Desenvolvimento em Revista V. 7, N. 1, jan-jun/2021, p. 100-121. ISSN online: $2446-8738$

Artigo recebido em: 12/05/2021

Artigo aprovado em: 12/07/2021

Figura 5 - Análise fatorial de correspondência (AFC)

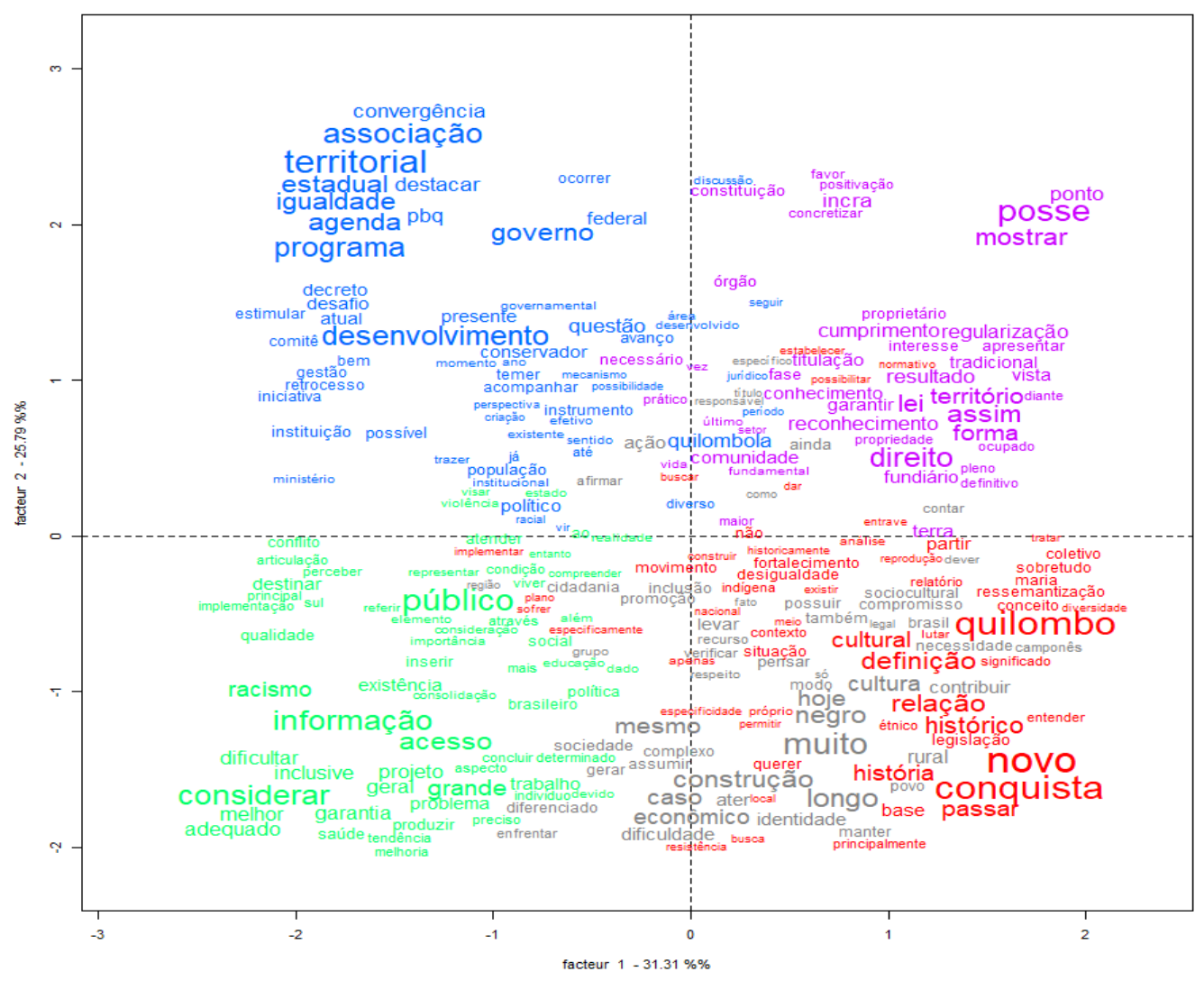

Fonte: Elaborada pelos autores a partir do software IRAMUTEQ (2021).

Por último, tem-se a Análise de Similitude (AS), onde se realiza a ligação das palavras do corpus textual por uma estrutura de construção dos textos e coocorrências importantes. Por meio da Figura 6, que representa um filograma e a conectividade das palavras por seus ramos, nota-se que a palavra central, dentro dessa construção gráfica, é: "quilombola", que se relaciona com o tema central desse artigo e que faz ligação direta com as demais palavras centrais das ramificações, que seriam i) "político", ii) "público", iii) "terra", vi) "comunidade", v) "não" e vi) "como".

A palavra central "quilombola" tem sua importância evocação central para discussão por ser o principal tema estudado pelos artigos analisados e está ligada diretamente à temática, por isso que todos acabam abordando de maneira central a referida palavra. A árvore fortalece, portanto, a centralidade dos termos "quilombola" (maior ocorrência) e obteve forte ligação com os vocábulos "comunidade", "político" e "público". A palavra "comunidade" esteve relacionada a "buscar", "direito", "negro" 


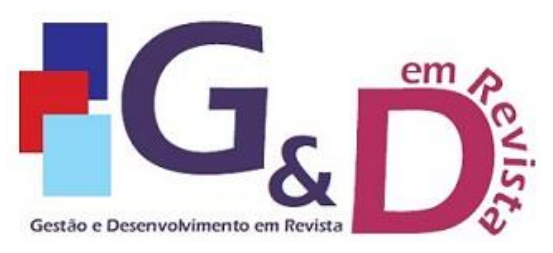

Gestão e Desenvolvimento em Revista V. 7, N. 1, jan-jun/2021, p. 100-121. ISSN online: $2446-8738$

Artigo recebido em: 12/05/2021

Artigo aprovado em: 12/07/2021

e "identidade", por exemplo. Enquanto que o vocábulo "político" ligou-se a questões sobre "desenvolvimento", "social" e "cultural".

Figura 6 - Análise de Similitude do corpus textual

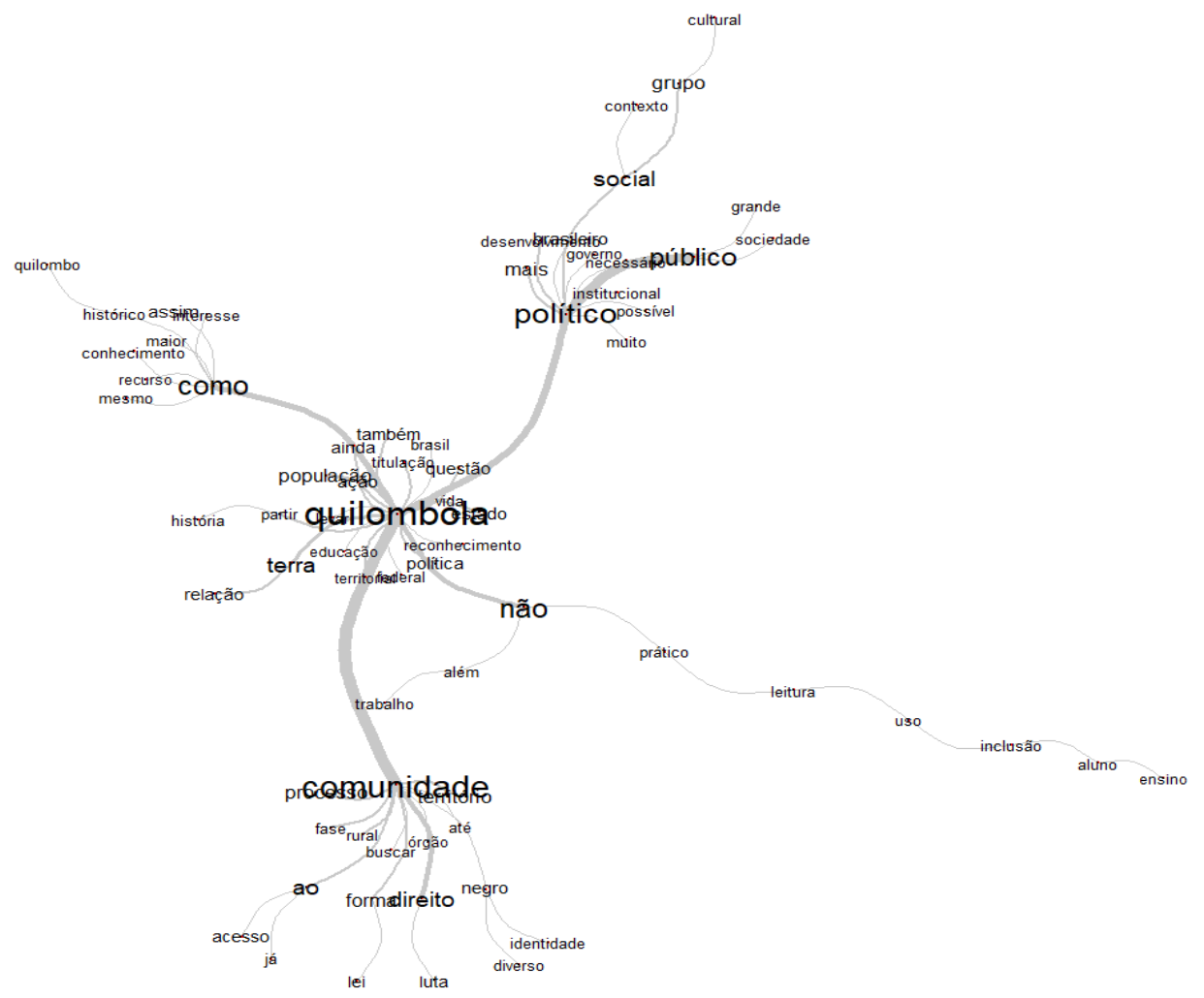

Fonte: Elaborada pelos autores a partir do software IRAMUTEQ (2021).

\section{NOTAS CONCLUSIVAS}

Ao analisar todos os trabalhos que foram coletados através do IRAMUTEQ, verificaram-se as diversas formas com que as comunidades quilombolas são atingidas, direta ou indiretamente, pelas políticas públicas existentes, ou a falta delas. Viu-se que a maioria das políticas públicas para comunidades quilombolas são consideradas recentes, pois a maior parte foi implementada a partir dos anos de 2004, ainda que já existissem desde a constituição de 1988 com a Fundação Cultura Palmares. Por meio dos trabalhos analisados, notou-se que a política governamental é a que mais influência o dia a dia das comunidades. Sendo assim, as políticas públicas desenvolvidas em âmbito federal, estadual ou municipal são as que mais podem contribuir para os avanços e garantias dos direitos sociais destas comunidades. 
Mesmo com grandes processos deixando a desejar, percebe-se, também, que em algumas áreas do Brasil, principalmente no Nordeste, essas políticas públicas para os quilombos são implementadas de maneira mais incisiva, muito por conta de maior parte das comunidades remanescentes de quilombolas se situarem nessa região, mas também pelo entendimento de que é preciso preservar e fazer o reparo histórico das oportunidades que foram tiradas ao longo dos anos.

Para que haja mudanças essenciais são necessárias mudanças comportamentais e governamentais na sociedade, que se cumpram as políticas públicas fundamentais, direito de todo cidadão, independentemente de sua condição na sociedade, e que as políticas públicas de fato consigam atingir o objetivo de desenvolvimento social e humano, pois apenas dessa forma conseguir-se-á atingir o objetivo principal de uma sociedade igualitária.

Do ponto de vista acadêmico, as pesquisas relativas aos temas historicamente marginalizados, tais como agricultura familiar, comunidades tradicionais, etc. têm ganhado espaço, entre outros fatores, por conta das políticas públicas. Destaca-se como exemplo a criação da Universidade da Integração Internacional da Lusofonia Afro-brasileira (UNILAB) em 2010 nos estados do Ceará e da Bahia. Como disponível no site da referida instituição, seu objetivo é "contribuir com a integração entre o Brasil e os demais países membros da Comunidade dos Países de Língua Portuguesa (CPLP), especialmente os países africanos, bem como promover o desenvolvimento regional e o intercâmbio cultural, científico e educacional".

Outra expressão cultural que assegura e evidencia a cultura negra no Nordeste é o Maracatu cearense. Fortaleceu-se enquanto festa popular que expressa à valorização da cultura afro-brasileira no estado do Ceará a partir de acontecimentos que the dão visibilidade como patrimônio material e cultural a nível municipal e nacional. Tais acontecimentos foram, por exemplo, a Lei Municipal $\mathrm{n}^{\circ}$ 5.827, de 05 de dezembro de 1984, que estabelecera o dia 25 de março como a data comemorativa ao Dia do Maracatu cearense, a criação, também, em 1984 do Museu do Maracatu, a inserção dos maracatus no ambiente acadêmico mediante pesquisas sobre suas temáticas, o empoderamento dos grupos por meio de investimentos financeiros proporcionados pelos editais do carnaval, bem como projetos de captação de recurso, e o acionamento das políticas de registro do 
patrimônio cultural imaterial dentro do município de Fortaleza e nacionalmente (SOUZA, 2017).

O Museu do Maracatu surge em meio a um conjunto de circunstâncias que estão associadas ao reconhecimento e à valorização dos grupos de maracatu existentes em Fortaleza, tais como: a definição das tradições cearenses, elencando o maracatu como símbolo de identidade regional, e o desenvolvimento do potencial turístico (cultural) no Ceará, especialmente na capital. Sob a perspectiva do potencial turístico, o debate existente era sobre a possibilidade de o Maracatu cearense, enquanto expressão cultural, assumir papel análogo ao Frevo e aos Maracatus Nação no carnaval de Pernambuco (SOUZA, 2017).

Por fim, pode-se afirmar que são inúmeros os trabalhos futuros que podem surgir a partir desta pesquisa relacionando os quilombos, de forma mais específica, com os eixos do desenvolvimento humano, a saber: a economia, o meio ambiente, a educação, a cultura, as instituições, etc. Acredita-se que a divulgação de trabalhos acadêmicos, tanto de pesquisa quanto de extensão, sobre tais temáticas são de grande valia na contribuição para este desenvolvimento.

\section{REFERÊNCIAS}

ARAÚJO, Allyne dos Santos et al. ANÁLISE SOCIOECONÔMICA DE AGRICULTORES DA COMUNIDADE QUILOMBOLA DO ABACATAL, ANANINDEUA, ESTADO DO PARÁ, BRASIL. Biota Amazônia (Biote Amazonie, Biota Amazonia, Amazonian Biota), [S.1.], v. 7, n. 1, p. 30-37, mar. 2017.

BOSI, Alfredo: A Escravidão Entre dois Liberalismo; in: Dialética da Colonização. São Paulo. Companhia das Letras, 1992.

BRANDÃO, André Augusto; JORGE; Amanda Lacerda: Congresso Conservador e Ameaças aos Direitos Quilombolas; in: Revista de Políticas Públicas, vol. 22, núm. 2, p 711$731,2018$.

BRASIL: Programa Brasil Quilombola; in: Guia de Políticas Públicas para Comunidades Quilombolas, Brasília, 2013.

BRASIL. Universidade de Integração Internacional da Lusofonia Afro-brasileira (UNILAB). UNILAB Institucional. Disponível em: https://unilab.edu.br/institucional-2/. Acesso em 10 de maio de 2021.

CARVALHO, Roberta Monique Amâncio; LIMA, Gustavo Ferreira da Costa: Comunidades Quilombolas, Territorialidade e a Legislação no Brasil: Uma Análise Histórica; in: Revista de Ciências Sociais, n. 39, p. 329-346, out. 2013. 


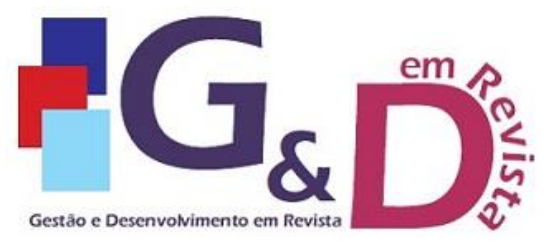

Gestão e Desenvolvimento em Revista V. 7, N. 1, jan-jun/2021, p. 100-121. ISSN online: $2446-8738$ Artigo recebido em: 12/05/2021 Artigo aprovado em: 12/07/2021

CHAVES, Leilane Oliveira; SILVA, Edson Vicente da: Comunidades Negras no Ceará: da Invisibilidade à Formação dos Quilombos Contemporâneos; in: Novos Cadernos NAEA v. 20, n. 3, p. 147-160, set-dez 2017.

COSTA, Eliane Silvia; SCARCELLI, Ianni Regia: Psicologia, Política Pública para a População Quilombola e Racismo; in: Psicologia. USP, vol.27, n.2, 2016.

DUNCK DALOSTO, João Augusto; DUNCK DALOSTO, Cássius: Políticas Públicas e os Quilombos no Brasil: da Colônia ao Governo Michel Temer; in: Revista de Políticas Públicas, São Luís, vol. 22, núm. 1, p. 545-564, 2018.

FERNANDES, Florestan: Significado do Protesto Negro. São Paulo: Cortez: Autores Associados, 1989. - (Coleção polêmicas do nosso tempo; v. 33).

FUNDAÇÃO OSWALDO CRUZ (FIOCRUZ). Políticas Públicas e Modelos de Atenção e Gestão à Saúde. Disponível em: https://portal.fiocruz.br/politicas-publicas-e-modelos-deatencao-saude. Acesso em: 25 jul. 2020.

LUCENA, Cecília Sabrina de Sousa; LIMA, Francisca Elizonete de Souza; PEREIRA, Camila da Silva: A Agricultura Familiar na Comunidade Quilombola Pêga, em Portloalegre - RN; in: GEOTemas, Pau dos Ferros, Rio Grande do Norte, Brasil, v.6, n.1, p.51-66, jan./jun. 2016.

MOURA, Clóvis: Os quilombos e a Rebelião Negra. São Paulo. Editora Brasiliense S.A., 1986 - (Tudo é História; $5^{\text {a }}$ edição).

OXFAM BRASIL. A distância que nos une: o retrato das desigualdades brasileiras, 2017. Disponível em: https://www.oxfam.org.br/um-retrato-das-desigualdades-brasileiras/adistancia-que-nos-une/ Acesso em 21 de setembro de 2020.

PERES, Élkila de Menezes; MOURA, Paulyana dos Santos; COSTA, André Azevedo: Investimentos para a Educação Quilombola no Ceará: Entre a Legislação, Políticas Educacionais e Desafios da Realidade; in: Anais do III Seminário Anual da Rede Mapa, 2018.

PÊSSOA, Jaciara Maria de Medeiros: (Re) Construindo a História Afrobrasileira e Indígena; in: IV Colóquio de História. UNICAMP, nov. 2010.

REIS, João José; GOMES, Flávio dos Santos: A Liberdade por um Fio: História dos Quilombos no Brasil. São Paulo. Companhia das Letras, 1996.

RODRIGUES, Joyce Maria: Políticas Públicas de Desenvolvimento Territorial para a População Quilombola: Algumas Considerações; in: Cadernos Ceru v. 25, n. 2, 2015.

SALVIATI, Maria Elisabeth: Manual do Aplicativo Iramuteq. Planaltina, março de 2017. 
SANTOS, Danilo Moreira dos: Os Quilombos e sua Inserção nas Políticas Públicas: subsídios à discussão da política de ATER quilombola; in: Revista de Políticas Públicas. Brasil, v.21, n. 2, p. 1019-1043, 2017.

SANTOS, Edmilson Santos et al. Offer of Schools of Quilombola School Education Center in the Northeast/BR. Educação \& Realidade, [S.L.], v. 44, n. 1, p. 1-22, 2019. FapUNIFESP (SciELO). http://dx.doi.org/10.1590/2175-623681346.

SCHMITT, Alessandra; TURATTI, Maria Cecõlian Manzoli; CARVALHO, Ana Celina Pereira de: A Atualização do Conceito de Quilombo: Identidade e Territórios nas

Definições Teóricas; in: Comunicação de Resultados de Pesquisa/ Research Result: Ambiente \& Sociedade - Ano V - No 10 - 1o Semestre de 2002.

SILVA, André Ricardo Fonsêca da: Políticas Públicas para Comunidades Quilombolas: uma luta em construção; in: Revista de Ciências Sociais, n 48, p. 115-128, 2018.

SILVA, David da; LIMA, Ivan Costa: Quilombos no Ceará: Desafio ao Acesso de Direitos aos Territórios; in: IV Congresso Nacional Africanidades e Brasilidades: Direitos Humanos e Políticas Públicas, set. 2018.

SILVA, David da; LIMA, Ivan Costa: Territórios Quilombolas no Ceará: Educação, Processo Histórico e Identidades; in: Brazilian Journal of Development, Curitiba, v. 5, n. 6, p. 5814-5827, jun. 2019.

SOARES, Iris Pontes: Conflitos Socioambientais e a Ameaça a ao Processo de Demarcação de Terras Quilombolas no Brasil; in: Revista de Políticas Públicas, vol. 22, núm. 2, p. 687-709, 2018.

SOUZA, Celina: Introdução Políticas Públicas: uma revisão da literatura; in: Sociologias, Porto Alegre, ano 8, nº 16, jul/dez 2006, p. 20-45.

SOUZA, Marli Aparecida Rocha; WALL, Marilene Loewen; THULER, Andrea Cristina de Moraes Chaves; LOWEN, Ingrid Margareth Voth; PERES, Aida Maris: The use of IRAMUTEQ software for data analysis in qualitative research; in: Revista da Escola de Enfermagem, USP. São Paulo, 2018.

SOUZA, Marcelo Renan Oliveira de. Museu do Macaratu do Ceará como Instrumento no Processo de Patrinomialização dos Maracatus de Fortaleza. Revista Memorare, Tubarão, SC, v.4, no 1, p. 165-189, janeiro, 2017.

URQUIZA, Antônio Hilário Aguilera e SANTOS, Lourival dos: Regularização fundiária de comunidades quilombolas em Mato Grosso do Sul/Brasil; in: Revista Brasileira de Políticas Públicas, ago/2017, volume 7, n² p. 232-247.

VELLOSO, Maria Jacy Maia; CASTANHEIRA, Maria Lúcia: Inclusão Digital e Práticas de Leitura em um Telecentro de uma Comunidade Quilombola; in: Revista Diálogo

Educacional, Curitiba, v. 19, n. 60, p. 288-307, jan. - mar., 2019. 


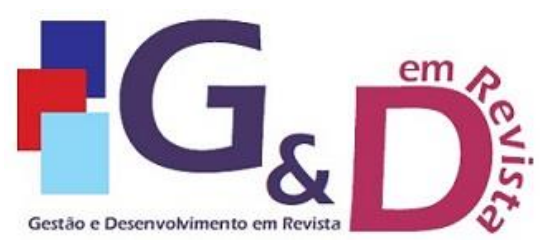

Gestão e Desenvolvimento em Revista V. 7, N. 1, jan-jun/2021, p. 100-121. ISSN online: $2446-8738$

Artigo recebido em: 12/05/2021

Artigo aprovado em: 12/07/2021

VIZEU CAMARGO, Brigido; JUSTO, Ana Maria: IRAMUTEQ: Um Software Gratuito para Análise de Dados Textuais; in: Temas em Psicologia. Ribeirão Preto, vol. 21, núm. 2, p. 513-518, dez. 2013. 